\title{
PRIORITIZING THE PARTNER'S ENJOYMENT \\ A population-based study on young Swedish women with experience of pain during vaginal intercourse
}

Eva Elmerstig, RN, RM, $\mathrm{PhD}^{1,2}$, Barbro Wijma, $\mathrm{MD}, \mathrm{PhD}^{2}$, Katarina Swahnberg, RN, $\mathrm{PhD}^{2,3}$

From the ${ }^{1}$ Faculty of Health and Society, Malmö University, Sweden, the ${ }^{2}$ Unit of Gender and Medicine, Department of Clinical and Experimental Medicine, Faculty of Health Sciences, Linköping University, Sweden, and ${ }^{3}$ Department of Health and Caring Sciences, Faculty of Health and Life Sciences, Linnaeus University, Sweden

Correspondence:

Eva Elmerstig

Faculty of Health and Society

Malmö University

SE-205 06 Malmö, Sweden

Phone: + 46406657490

Email: eva.elmerstig@mah.se

\begin{abstract}
The present study examines the prevalence of women who continue to have vaginal intercourse (VIC) despite pain, avoid telling the partner, and feign enjoyment. It also considers the reasons for this behavior.

A sample of 1566 female senior high school students (aged 18-22 years) completed a questionnaire concerning their experiences and attitudes toward their body and sexuality.

Forty-seven percent (270/576) of those women who reported pain during VIC continued to have VIC despite the pain. The most common reasons were that they did not want to spoil sex for or hurt the partner by interrupting VIC. Feigning enjoyment and not telling the partner about their pain were reported by $22 \%$ and $33 \%$ respectively. Continuing to have VIC despite pain was associated with feelings of being inferior to the partner during sex, dissatisfaction with their own sex lives, and feigning enjoyment while having pain.

Pain during VIC is reported by every third young Swedish woman, and almost half of those still continue to have VIC. The major reason given is noteworthy --- prioritizing the partner's enjoyment before their own --- and indicates that young women who continue to have VIC despite pain take a subordinate position in sexual interactions.
\end{abstract}

Keywords: female health, gynecological pain, psychosomatic gynaecology, sexual health, women's sexuality 


\section{Introduction}

There has been only limited research focusing on the prevalence of pain and/or physical discomfort associated with vaginal intercourse (VIC) in young women. Due to different types of pain during VIC, as well as different definitions and study populations, prevalence studies provide diverse estimates in young and adult women. Recently, studies have also paid attention not only to pain during VIC, but also to physical discomfort and other sensations associated with VIC, such as itching and burning pain, which have been suggested as symptoms of partial vaginismus [1, 2]. (Henceforth in this article we use the term 'pain', as equivalent to pain and/or discomfort). A previous study [3] in Sweden, found that $49 \%$ of women who had experienced VIC during the previous month, and who had consulted a youth center, had experienced pain associated with VIC during that period. Another study in Sweden [4] showed that 34\% of women (aged 12-26) who consulted youth centers reported pain/burning sensations, and 23\% reported itching during or after intercourse. A populationbased study in Canada [5] found that as many as $20 \%$ of sexually active women aged 12-19 reported chronic dyspareunia.

Despite several studies exploring physiological and psychosexual mechanisms, it still remains uncertain which factors contribute to the development and maintenance of diverse pain during/after VIC [6-8]. It is known that pain experienced during VIC is not an isolated phenomenon; it also influences, among other things, emotions and sexual relationships. In a study by Kaler [9], women with vulvar pain described themselves as being "degendered" or "defeminized" due to difficulty in completing VIC. As previously identified, an unknown proportion of women continue to have VIC despite pain [10-12]. On theoretical grounds, repeated painful VIC might elicit a vaginistic reflex $[13,14]$. It has been suggested that the vaginistic reaction initially is a general defense mechanism, a protective symptom appearing when the woman is exposed to a perceived threat, such as pain during VIC [13-15]. When the woman are exposed to repeated painful intercourse, the protective mechanism, which is an unconditioned response, becomes a conditioned response: a vaginistic reflex $[15,16]$. It is therefore highly likely that continuing to have VIC despite pain, in some cases might contribute to prolonged pain during VIC and increase the problem. A qualitative study [10], investigated young women's motives for continuing to have VIC despite pain, and found that the women were striving to reach their ideal image of being a woman. Their ideal woman had several characteristics, such as willingness to have VIC, perception of their partner's sexual needs, and ability to satisfy the partner. The women focused on the partner and paid less attention to their own sexual pleasure [10]. The findings by Ayling an Ussher [11] similarly showed that women felt shame and guilt for experiencing pain during VIC because it affected their ability to satisfy their partners [11].

Because pain during VIC (we use during VIC as equal to during and/or after VIC) in many cases seems to start at a young age, and an unknown proportion of young women who continue to have VIC despite pain run the risk of developing vaginismus, there is a need for studies exploring young populations. Therefore, the present study aimed to estimate in young women:

(1) the prevalence of women who continue to have VIC despite pain, who feign enjoyment, and who do not tell the partner about the pain; and (2) their reasons for those actions.

On the basis of a previous qualitative study [10] we explore ten hypotheses based on the theory: women sacrifice their own pleasure and put the partners' interest first, in their striving to become an ideal woman and a "perfect girlfriend".

The ten hypotheses are as follows: A greater proportion of young women who experience pain during VIC will, in comparison with those who do not: (hypothesis 1) have difficulty refusing sex when the partner wants it, (hypothesis 2) feel inferior to the partner during sex, 
(hypothesis 3) regard the partner's satisfaction as more important than their own, and (hypothesis 4) feel dissatisfaction with their own sex life.

A greater proportion of young women who continue to have VIC despite pain will, in comparison with those who have pain during VIC, but do not continue to have VIC: (hypothesis 5) have difficulty refusing sex when the partner wants it, (hypothesis 6) feel inferior to the partner during sex, (hypothesis 7) regard the partner's satisfaction as more important than their own, (hypothesis 8) feel dissatisfaction with their own sex life, (hypothesis 9) feign enjoyment, and (hypothesis 10) avoid telling the partner about their experiences of pain.

\section{Methods}

\section{Participants}

The study involved female senior high school (upper secondary school) students 18-22 years old, representing two counties in the south of Sweden including small- and medium- sized cities and countryside areas, as well as university and industrial cities.

To obtain breadth in sociodemographic background factors, participants from both public and private schools and both practical/vocational and general/economic classes were included.

Eighty-four (84/134) public and private senior high schools were contacted. Thirty-one schools did not participate because of a lack of time in the students' schedules, and one school refused to participate due to the nature of the study topic.

The final target group consisted of 226 practical/vocational and general/economic classes at 52 senior high schools in the two counties. The inclusion criteria of participants were being female, $\geq 18$ years of age, and able to read and speak Swedish.

Students not present in the classrooms at the time of data collection numbered 544, and the reasons given for their absence were illness, truancy, school trip, study tour, individual work, etc. At the time of data collection, 1616 women were present in the classrooms, but 45 women were excluded due to age $<18$ years. Thus 1571 female students were eligible, four women declined participation, and one woman did not participate because of a handicap. Finally, 1566 women were included. These were characterized as practical/vocational (810), general/economic (756) from the first county (911) and the second county (655).

\section{Procedure}

An information letter stating the background, aim and procedure of the study was sent to the principals of the high schools, followed by telephone calls from the first author (EE), to get approval.

During a three-month period, EE and three to six assistants visited the schools, where the participants filled in the questionnaires (25-40 minutes) in the classroom or in a lecture hall, during a lesson included in the ordinary weekly schedule. 


\section{Ethical considerations}

Questions concerning sexual issues require special ethical attention. The participants received oral and written information about the study, and were told that participation was voluntary, and that they could withdraw their decision to participate at any time, without giving a reason. A completed questionnaire was considered to represent giving informed consent.

To facilitate seclusion and minimize peer influence, the desks were separated if possible, and each participant received a screen to place on the desk, which prevented neighbors from seeing the respondent's answers. In the questionnaire the alternative "not relevant for me" was available for those who had no personal experience of what was asked for in specific questions. The participants left the completed questionnaire in a box, which was closed and collected directly afterwards by EE. In case anybody wanted personal counseling, all the participants received a card with a telephone number for local youth centers, police, RFSU (Swedish Association for Sexuality Education) [17] and the nurse and social worker at each school.

The study was approved by the central ethical review board, Stockholm (Dnr: Ö 15-2007).

\section{Measures}

The questionnaire was constructed by the research team and was based on clinical experience, an extended version of a questionnaire used by Elmerstig et al. [3], results from Elmerstig et al.'s qualitative study [10], other research within the area, and scrutinizing of existing questionnaires and instruments [18-21] used for investigation of sexual issues. A pilot study was performed with three third year high school classes in another county. Statistics Sweden tested the questions to improve the quality of the questionnaire [22, 23]. Two different research groups independently affirmed the face and content validity of the final version of the items. A final revision of the questionnaire was carried out based on suggestions from Statistics Sweden, the two research groups, and the results from the pilot study.

The questionnaire consisted of 201 questions divided into eight sections.

As background variables we included age, study program, ethnicity, school region, smoking habits, and age at first VIC.

Our dependent variables in this study were concerned with the present situation: experience of pain during VIC and continuing to have VIC despite pain.

The first variable, "experience of pain during VIC", was based on the question "How often do you experience pain and/or physical discomfort, for example itching, smarting pain, pressure, burning or a cutting feeling at the beginning, during and/or after VIC?”

If the women had experienced pain and/or discomfort during VIC they were asked to answer the questions for the second dependent variable: "Do you ever continue to have VIC despite pain/discomfort?", and the independent variable "Do you ever feign enjoyment despite pain/discomfort?” Answers were given on a six-grade scale: Never, Seldom, Sometimes, Fairly frequently, Almost every time and Every time. We dichotomized the answers into Yes and No, by regarding the answers Sometimes to Every time (3-6) as indicating Yes and Never to Seldom (1-2) as indicating No. The women were also asked if they had told the partner about their experience of pain/discomfort, with the answer alternatives Yes or No.

Participants who had reported that they continued to have VIC, and/or feigned enjoyment despite pain and/or discomfort during VIC were asked for their reasons for doing so. The women were given a range of pre-formulated options to select from, and an empty space was also provided to allow for other answers. One or more alternatives could be selected.

Partner satisfaction was estimated by means of three items. Participants were asked "Do you ever have difficulty refusing to have sex if your partner wants sex but you don't?”, “Do you 
ever feel inferior to your partner during sex?" and "Do you ever think that it is more important that your partner is satisfied than you, while having sex?” The answering alternatives (sixgrade scale) consisted of Never, Seldom, Sometimes, Fairly frequently, Almost always and Always. We dichotomized the answers into Yes and No, after regarding the answers Sometimes to Always (3-6) as indicating Yes and Never to Seldom (1-2) as indicating No.

Participants were also asked to assess their own satisfaction with their sex life by stating to what extent they were satisfied/dissatisfied on a six-grade scale from Very satisfied to Very dissatisfied. These answers were dichotomized into satisfied (1-3) and dissatisfied with sex life (4-6).

\section{Analysis}

Statistical analyses were performed using IBM SPSS Statistics version 19.0 (Chicago, IL).

We used Pearson Chi-square tests to assess the statistical significance of prevalence of pain, and continuing to have VIC despite pain, between groups. Binary logistic regression was used to test associations between continuing to have VIC despite pain and significant factors in the univariate analyses.

Only observed differences with p-values $<.05$ were considered as statistically significant.

\section{Results}

The mean age in our sample of 1566 females (response rate 1566/1571 = 99,7\%) was 18.3 years (range 18-22; standard deviation 0.54). Eight percent of the participants (Table 1) and $15 \%$ of their parents were born outside Sweden. The majority (90\%) reported heterosexual identity, 5\% reported homosexual/bisexual identity, and 5\% did not know. The majority (80\%) of the participants reported having had VIC, and mean age at first VIC was 15.5 years (range, 7-20; standard deviation 1.48) (Table 1). Continuing to have VIC despite pain was more commonly reported in women who had experienced their first VIC when they were between 7-14 years and 17-20 years, and less reported among those who had experienced their first VIC when they were between 15-16 years old (Table 1).

We found only minor differences between the two counties regarding background variables, and in the prevalence of behavior related to our outcome measures, which is why we treat the two samples as one.

Almost half (47\%, 591/1259) of the women who had had VIC reported experience of pain and/or discomfort during VIC (Table 2).

The most common reason for continuing to have VIC despite pain was “I don't want to spoil things for my partner" (42\%)(Table 3). One of the most common reasons given for feigning enjoyment despite pain was “The partner may be disappointed if I don't enjoy VIC" (59\%) (Table 3).

Hypotheses 1-4 were supported. Difficulty refusing sex when the partner wants it, feeling inferior to the partner during sex, regarding the partner's satisfaction as more important than their own, and feeling dissatisfaction with their sex life were more frequently reported among women who experienced pain during VIC than among women who did not (Table 4).

It was also notable that the majority of the women regarded the partner's satisfaction as more important than their own, whether or not they experienced pain during VIC (Table 4).

Hypotheses 5-8 were supported. Among women who continued to have VIC despite pain, a significantly higher proportion than those who did not continue to have VIC despite pain had difficulty refusing sex when the partner wanted it, felt inferior to the partner during sex, regarded the partner's satisfaction as more important than their own, and felt dissatisfaction with their sex life (Table 4). 
Feigning enjoyment despite experience of pain was more commonly reported among women who continued to have VIC than among those who did not continue to have VIC, but there were no differences in not telling the partner about their experience of pain (Table 4). Thus, hypothesis 9 was confirmed; hypothesis 10 was not.

The multivariate findings provided support for a relationship between continuing to have VIC despite pain and feeling inferior to the partner during sex, dissatisfaction with one's own sex life and feigning enjoyment despite pain (Table 5).

Table 1. Background characteristics of all participants $(n=1566)$ and in relation to continuing to have VIC despite pain $(n=576)$.

\begin{tabular}{|c|c|c|c|c|c|c|c|}
\hline & \multicolumn{2}{|c|}{$\begin{array}{l}\text { All participants } \\
\qquad \underline{n=1566}\end{array}$} & \multicolumn{5}{|c|}{$\begin{array}{l}\text { Participants who continue to } \\
\text { have VIC despite pain } \\
\qquad n=576\end{array}$} \\
\hline & & $\%$ & \multicolumn{2}{|c|}{$\begin{array}{c}\text { Yes } \\
n=270(\%)\end{array}$} & \multicolumn{2}{|c|}{$\begin{array}{c}\text { No } \\
n=306(\%)\end{array}$} & $p$ \\
\hline Age & & & & & & & 0.616 \\
\hline 18 years & 1213 & 77.7 & 205 & 75.9 & 232 & 76.1 & \\
\hline 19 years & 291 & 18.6 & 51 & 18.9 & 61 & 20.0 & \\
\hline 20 years & 52 & 3.3 & 14 & 5.2 & 11 & 3.6 & \\
\hline 21-22 years & 6 & 0.4 & 0 & 0 & 1 & 0.3 & \\
\hline Study program & & & & & & & 0.470 \\
\hline Practical/vocational & 810 & 51.7 & 141 & 52.2 & 169 & 55.2 & \\
\hline General/economic & 756 & 48.3 & 129 & 47.8 & 137 & 44.8 & \\
\hline Ethnicity & & & & & & & 0.854 \\
\hline Born in Sweden & 1431 & 91.8 & 253 & 94.1 & 281 & 92.4 & \\
\hline Born in another Nordic country & 15 & 1.0 & 2 & 0.7 & 4 & 1.3 & \\
\hline $\begin{array}{l}\text { Born in Europe; outside the Nordic } \\
\text { countries }\end{array}$ & 69 & 4.4 & 7 & 2.6 & 9 & 3.0 & \\
\hline Born outside Europe & 44 & 2.8 & 7 & 2.6 & 10 & 3.3 & \\
\hline School region & & & & & & & 0.135 \\
\hline First county & 911 & 58.2 & 152 & 56.3 & 191 & 62.4 & \\
\hline Second county & 655 & 41.8 & 118 & 43.7 & 115 & 37.6 & \\
\hline Smoker & & & & & & & 0.219 \\
\hline Yes & 482 & 30.9 & 171 & 63.3 & 208 & 68.2 & \\
\hline No & 1076 & 69.1 & 99 & 36.7 & 97 & 31.8 & \\
\hline \multicolumn{8}{|l|}{ Have had VIC } \\
\hline Yes & 1259 & 80.4 & & & & & \\
\hline No & 306 & 19.6 & & & & & \\
\hline Age at first VIC ( $n=1239)$ & & & & & & & 0.002 \\
\hline $7-12$ years & 18 & 1.5 & 6 & 2.2 & 0 & 0 & \\
\hline $13-14$ years & 308 & 24.9 & 79 & 29.4 & 66 & 22.0 & \\
\hline $15-16$ years & 600 & 48.4 & 113 & 42.0 & 165 & 55.0 & \\
\hline $17-20$ years & 313 & 25.3 & 71 & 26.4 & 69 & 23.0 & \\
\hline
\end{tabular}


Note: Vaginal intercourse is equal to VIC, Internal dropout $=(0.2-1.6 \%)$

Table 2. Distribution of factors hypothesized to be

related to experience of pain during VIC $(n=591) *$

\begin{tabular}{lcc}
\hline & $\boldsymbol{n}$ & $\mathbf{\%}$ \\
\hline $\begin{array}{l}\text { Continue to have VIC despite experience of } \\
\text { pain }\end{array}$ & & \\
Yes & 270 & 46.9 \\
No & 306 & 53.1 \\
Feign enjoyment despite experience of pain & & \\
& 127 & 22.1 \\
Yes & 447 & 77.9 \\
No & & \\
Not telling the partner about & & \\
pain & 191 & 32.6 \\
Yes & 394 & 67.4 \\
No & & \\
\hline
\end{tabular}

Notes: Vaginal intercourse is equal to VIC.

Internal dropout $=(1.1-2.9 \%) *$ Experience of pain during

VIC was reported by 47\% (591/1259).

\section{Discussion}

The main findings of this population-based study show that: (i) pain during VIC in young women is highly prevalent; (ii) almost half of the women experiencing pain continue to have VIC despite pain; (iii) the women's reason for continuing to have VIC despite pain was that they regarded the partner's satisfaction as more important than their own; and (iv) continuing to have VIC despite pain was associated with feeling inferior to the partner during sexual situations, feeling dissatisfaction with their sex life, and feigning enjoyment.

The findings from the present study with the high rate of $47 \%$ of young women experiencing pain during VIC is in accordance with previous Swedish studies [3, 4] assessing pain during VIC. It is known that some women continue to have VIC despite pain [10-12], but as far as we know, there are no earlier studies estimating the prevalence of this actions. Therefore, we find the large proportion of women continuing to have VIC despite pain noteworthy. Theoretically, pain during VIC could cause a vaginistic reaction, initially as an unconditioned mechanism and, when repeated as a conditioned mechanism [13-15]. Therefore, an unknown proportion of young women who continue to have VIC despite pain run the risk of developing chronic pain associated with VIC. In the present study we further expand on why young women continue to have VIC despite pain. Our theory and our hypothesis derived from a previous qualitative study [10] were supported as we found that women with experience of pain more often had difficulties refusing sex, felt inferior to the partner and regarded the partner's satisfaction as more important, than women without such pain. Our findings align with previous findings on women with pain during VIC [11], where they felt pressure to have VIC within heterosexual relationships, and attached higher value to their partner's need for VIC than to their own need for pain-free sex [11]. Holland et al. [24] point out in their research about young people's sexuality that almost all the male and female youths defined "proper sex" as VIC, with male penetration culminating in male orgasm. 
Table 3. Distribution of women's reasons for continuing to have VIC $(n=270)$, and for feigning enjoyment despite pain during VIC $(n=127)$

\begin{tabular}{lcc}
\hline Reasons for continuing to have VIC despite pain (n=270) & n & \% \\
\hline 1. I don't want to spoil things for the partner by interrupting VIC & 112 & 41.5 \\
2. I feel foolish to interrupt VIC & 110 & 40.7 \\
3. I don't want to hurt the partner by interrupting VIC & 106 & 39.3 \\
4. The partner may be disappointed if I can't have VIC & 98 & 36.3 \\
5. I feel nasty if I have to interrupt VIC & 89 & 33.0 \\
6. I want the VIC to be over & 61 & 22.6 \\
7. I feel partner pressure to have VIC & 59 & 21.9 \\
8. I want to be a woman who is able to have VIC & 57 & 21.1 \\
9. I don't want to tell the partner about having pain & 50 & 18.5 \\
10. I want to avoid all nagging about VIC & 38 & 14.1 \\
11. I want to show the partner that he/she is good in bed & 31 & 11.5 \\
12. I feel societal pressure to be able to have VIC & 9 & 3.3 \\
13. Other reasons & 74 & 27.4
\end{tabular}

\section{Reasons for feigning enjoyment despite pain during VIC (n=127)}

1. The partner may be disappointed if I don't enjoy VIC

n \%

2. I don't want to tell the partner that I don't enjoy VIC

$75 \quad 59.1$

3. I feel partner pressure to be able to enjoy VIC

4. I want the VIC to be over

5. I want to show the partner that he/she is good in bed

In a qualitative study [25] with young women without experience of pain during VIC, it was found that diverse social processes such as social norms and demands had a negative impact on young women's chances of attaining equal sexual pleasure in heterosexual practice. The women described that some men took advantage of women's subordinated position, and the women felt a societal pressure to undervalue their own pleasure and focus on the partner's pleasure [25].

As we hypothesized, among women who continued to have VIC despite pain, a higher percentage felt dissatisfaction with their sex life than among those who did not continue. This dissatisfaction with sex life probably includes diverse factors, such as decreased sexual desire, and the experience of pain instead of pleasure during sexual activities [10]. Ailing et al. [11] found that women with pain during VIC took one of two different stances. Women who continued to have VIC despite pain, identified themselves as an "inadequate woman/sexual partner", which led to feelings of guilt, shame and decreased desire. If the woman instead had other forms of pain-free sexual activities, she reported an identity as an "adequate woman/sexual partner” [11]. 
When statistically significant variables were entered in a multivariate model, feeling inferior to the partner during sex, dissatisfaction with their sex life, and feigning enjoyment despite pain were associated with continuing to have VIC despite pain. This may be seen as indicating women's expectations that femininity involves being in a subordinated position, where they want the partner to be happy, and where they sacrifice their own satisfaction. 
Table 4. Experience of pain during VIC and continuing to have VIC despite pain in relation to having difficulty to refusing sex, feeling inferior to the partner, regarding the partner satisfaction as more important than their own, dissatisfaction with their sex life, feigning enjoyment and not telling the partner about pain.

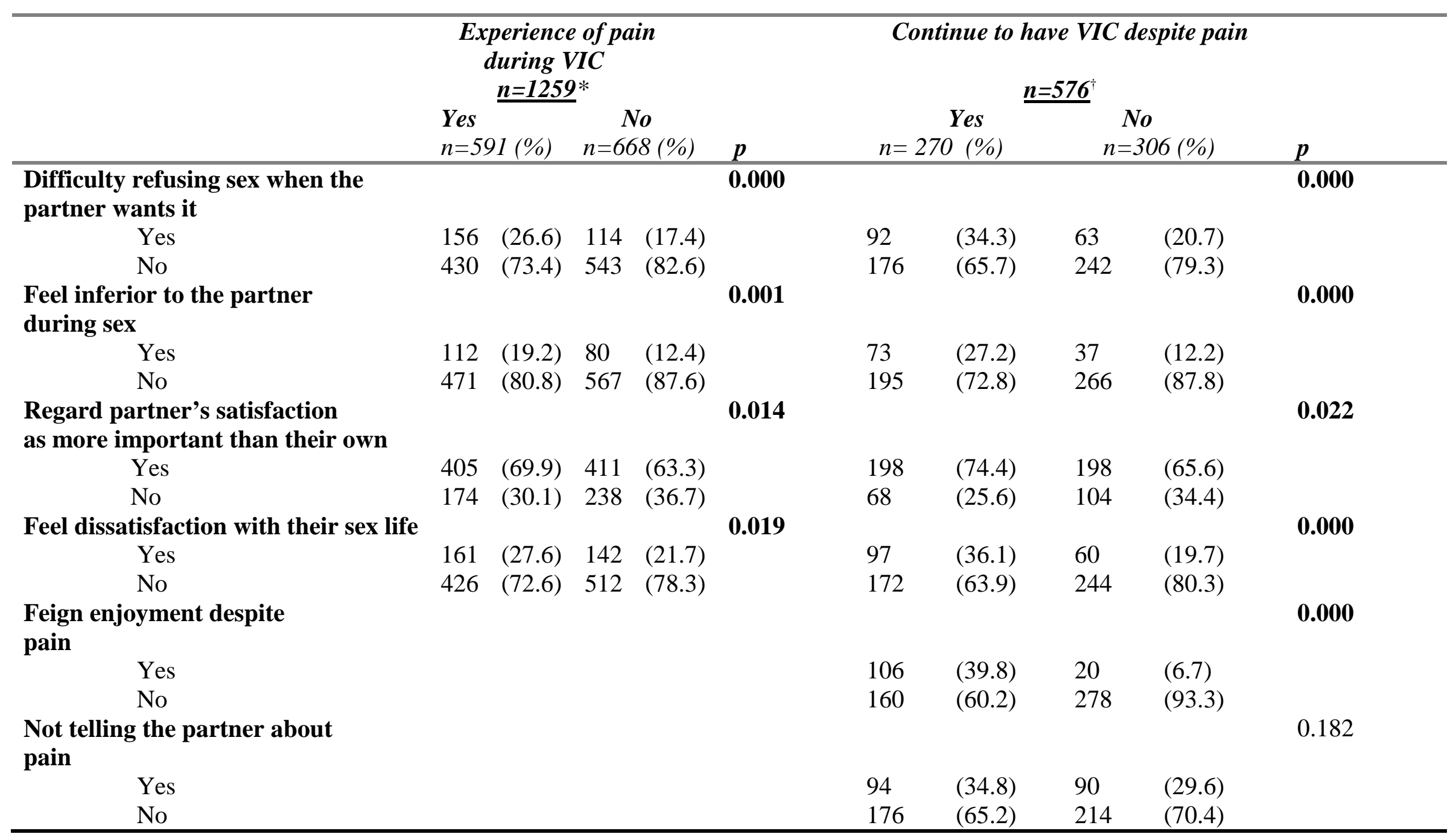


Notes: Vaginal intercourse is equal to VIC, Internal dropouts= $(0.3-3.1 \%){ }^{*}$ Includes only women who have reported experience of VIC ${ }^{\dagger}$ Includes only women who have reported experience of pain during VIC. 
Table 5. Adjusted odds ratios (OR) for associations between continuing to have VIC despite pain, in relation to having difficulty refusing sex, feeling inferior to the partner, regarding the partner's satisfaction as more important, dissatisfaction with their sex life and feigning enjoyment.

Continue to have VIC despite

pain

$\underline{n}=548$

\begin{tabular}{lcc}
$\begin{array}{l}\text { Variable } \\
\text { Difficulty refusing sex when the }\end{array}$ & $\begin{array}{c}\text { Adjusted } \\
\text { OR }\end{array}$ & $\begin{array}{c}\mathbf{9 5 \%} \\
\text { CI }\end{array}$ \\
\hline $\begin{array}{l}\text { partner wants it } \\
\begin{array}{l}\text { Feel inferior to the partner } \\
\text { during sex }\end{array}\end{array}$ & 1.20 & $0.77-1.87$ \\
$\begin{array}{l}\text { Regard the partner's satisfaction as more important than } \\
\text { their own }\end{array}$ & 1.10 & $1.10-3.02$ \\
$\begin{array}{l}\text { Feel dissatisfaction with their sex life } \\
\begin{array}{l}\text { Feign enjoyment despite } \\
\text { pain }\end{array}\end{array}$ & $\mathbf{1 . 7 6}$ & $1.14-2.72$ \\
\hline
\end{tabular}

Note: Vaginal intercourse is equal to VIC. Adjusted for age at first VIC and all included variables within the model.

When women continue to have VIC despite pain it creates a negative cognitive schema where the women feel guilt, decreased desire [10,11] and shame [11]. According to our current findings, they also felt inferior to the partner during sex and experienced dissatisfaction with their sex life. It may be presumed that if the women had instead had other pain-free sexual activities, they might have formed a different cognitive schema, experiencing sex as a pleasurable situation. Unfortunately, the findings that women feel inferior to their partners during sex, correspond with the societal pressure in young people's sexual life, where traditional masculinity norms are strong and maintain the women's subordinated position [24, 25]. Previous research indicates that young women who internalize norms of conventional femininity have inappropriate sexual health protection behavior to a greater extent [26]. Such findings raise the question of whether such traditional femininity norms are stronger in these women who continue to have VIC and/or feign enjoyment despite experiencing pain, than in women who do not.

Two other research groups $[27,28]$ found associations between young women's sexual experiences and how they conformed to gender norms, consisting of reduced ability to become aroused and achieve orgasm [27], and the experience of undermined sexual autonomy and lower sexual satisfaction [28]. Considering these [27, 28] results, it is conceivable that the women in our study who continued to have VIC despite pain also decreased their likelihood of reaching orgasm because they had reduced sexual autonomy, and because of decreased sexual desire and arousal due to the experience of pain. 
A limitation of this study is the cross-sectional design, which restricted our chance to examine the causal directions of the observed associations. A choice of school setting for data collection is dependent on the principals' approval. One limitation is that there were a higher proportion of schools in the second county that declined participation, than the first county. One explanation for this is that we had a shorter period of time for data collection in the second county, which gave the principals less time to plan our data collection in the students' schedules. However, the schools that declined participation represented both private and public schools and different cities and areas. Social desirability bias is always a concern in studies assessing sensitive issues like sexuality [29]. In the present study the participants filled out the questionnaire in a classroom or a lecture hall. We reduced the potential risk of schoolmates affecting the validity of the data, by separating the desks and providing a screen. In addition, the alternative "not relevant for me" was available in the questionnaire for those who had no personal experience of what was asked about. Another shortcoming is that nonattendance was higher than we expected but did not vary depending on whether the investigation had been announced in advance or not. However, the response rate was constantly high among the students available in the classrooms. Similar pattern of high numbers of non-attendance in school-based sexual health research has been seen in other studies [30, 31]. Furthermore, we did not do a power calculation. However, retrospectively we found that we had enough participants. Another limitation is that our sample is not representative of Sweden as a whole; no big cities were included, nor were the northern part of Sweden represented. It is difficult to say if our findings would have been different with a representative national sample, e.g., if big cities had been included. However, other Swedish studies assessing diverse questions about adolescents' sexuality have not found any differences between urban and rural areas [32-33]. In addition, our prevalence rate of women experiencing pain during VIC is in accordance with results from a study conducted in Stockholm, the biggest city in Sweden [4]. Furthermore, to obtain breadth in sociodemographic background factors, the participants came from both public and private schools, including both general/economic and practical/vocational classes. Another limitation is that the questionnaire was constructed by the authors. To reduce the effect of this shortcoming the questionnaire was based on our qualitative interviews with young women, with and without experience of pain during VIC, a pilot study was performed, and Statistics Sweden tested the questions to improve the validity.

In conclusion, this study portrays the complexity of "pain during VIC", and expands the understanding of the influences of gender norms on young women's sexuality. There is reason to be concerned about the large proportion of women experiencing pain during VIC and of women continuing to have VIC despite pain. Theoretically, women who continue to have VIC despite pain may run an increased risk of developing a chronic pain problem associated with VIC. It is obviously relevant for professionals working with young women such as physicians, psychologists, social workers and midwives to highlight the importance of young women's own satisfaction and discuss other sexual activities than VIC which are less likely to cause pain.

\section{Acknowledgements}

The authors are most grateful to the women participated in this study.

\section{Declaration of Interest:}


This research was supported by The Swedish Research Council, record No: 521-3003-5150, The Kempe-Carlgrenska Foundation, The Solstickan Foundation and Lions Research Foundation. There are no financial or other relationships that might lead to a conflict of interest. The authors alone are responsible for the content and writing of the paper.

\section{References}

1. Engman M, Wijma K, Wijma B. Itch and burning pain in women with partial vaginismus with or without vulvar vestibulitis, J Sex Marital Ther, 2007, 33(2): 171186.

2. Engman M, Wijma K, Wijma B. Post-coital burning pain and pain at micturition: early symptoms of partial vaginismus with or without vulvar vestibulitis? J Sex Marital Ther, 2008, 34(5): 413-428.

3. Elmerstig E, Wijma B, Swahnberg K. Young Swedish women's experience of pain and discomfort during sexual intercourse, Acta Obstet Gynecol Scand, 2009, 88(1): 98-103.

4. Berglund AL, Nigaard L, Rylander E. Vulvar pain, sexual behavior and genital infections in a young population: a pilot study, Acta Obstet Gynecol Scand, 2002, 81(8): 738-742.

5. Landry T, Bergeron S. How young does vulvo-vaginal pain begin? Prevalence and characteristics of dyspareunia in adolescents. J Sex Med, 2009; 6:927-935.

6. Desrochers G, Bergeron S, Landry T, et al., Do psychosexual factors play a role in the etiology of provoked vestibulodynia? A critical review. J Sex Marital Ther, 2008, 34(3):198-226.

7. Farmer MA, Meston CM. Predictors of genital pain in young women. Arch Sex Behav, 2007, 36(6): 831-843.

8. Payne KA, Binik YM, Amsel R, et al., When sex hurts, anxiety and fear orient attention towards pain. Eur J Pain, 2005, 9(4): 427-436.

9. Kaler A. Unreal women: sex, gender, identity and the lived experience of vulvar pain. Feminist review, 2006, 82: 50-75.

10. Elmerstig E, Wijma B, Bertero C, Why do young women continue to have sexual intercourse despite pain? J Adolesc Health, 2008, 43(4): 357-363.

11. Ayling K, Ussher JM. "If sex hurts, am I still a woman?" the subjective experience of vulvodynia in hetero-sexual women. Arch Sex Behav, 2008, 37(2): 294-304.

12. Cacchioni T. Heterosexuality and "the Labour of Love": A contributions to Recent Debates on Female Sexual Dysfunction. Sexualities, 2007, 10(3): 299-320.

13. van der Velde J, Everaerd W, The relationship between involuntary pelvic floor muscle activity, muscle awareness and experienced threat in women with and without vaginismus. Behav Res Ther, 2001, 39(4): 395-408.

14. van der Velde J, Laan E, Everaerd W. Vaginismus, a component of a general defensive reaction. an investigation of pelvic floor muscle activity during exposure to emotion-inducing film excerpts in women with and without vaginismus. Int Urogynecol J Pelvic Floor Dysfunct, 2001, 12(5): 328-331.

15. Wijma B, Wijma K. A cognitive behavioural treatment model of vaginismus. Scand J Behav Ther, 1997, 26(4): 147-156. 
16. ter Kuile MM, van Lankveld JJ, de Groot E, et al., Cognitive-behavioral therapy for women with lifelong vaginismus: process and prognostic factors. Behav Res Ther, 2007, 45(2): 359-73.

17. RFSU (Swedish Association for Sexuality Education) [Internet]. [cited 2012 Aug 10]; Available from http://www.rfsu.se/sv/RFSU-kliniken/

18. Edgardh K. Tonåringar, sex och samlevnad [Teenagers, sex and personal relations] (In Swedish). Göteborg, Sweden: Förlagshuset Gothia, 1992.

19. Lewin B (ed), Fugl-Meyer K, Helmius, G, et al., Sex i Sverige. Om sexuallivet i Sverige 1996 [ Sex in Sweden. On the Swedish sexual life ] (In Swedish). Stockholm: Folkhälsouniversitetet, 1998.

20. Forsberg M. Brunettes and Blondes. Youth and sexuality in multicultural Sweden (In Swedish).Göteborg: Department of Social Work, Göteborg University, 2005.

21. Svedin CG, Priebe G. Selling sex in a population-based study of high school seniors in Sweden: demographic and psychosocial correlates. Arch Sex Behav, 2007, 36(1): 2132.

22. Bergman LR. Pretesting Procedures at Statistics Sweden's Measurement, Evaluation and Development Laboratory. Journal of Official Statistics, 1995, 11(3): 309-323.

23. Statistics Sweden. [Internet]. [cited 2012 Aug 10]; Available from http://www.scb.se/default 2154.aspx

24. Holland J, Ramazanoglu C, Sharpe S, et al., The male in the head- Young people, heterosexuality and power. London: the Tufnell Press; 2004.

25. Elmerstig E, Wijma B, Sandell K, Berterö C. "Sexual pleasure on equal terms": young women's ideal sexual situations. Journal of Psychosomatic Obstetrics \& Gynecology, 2012, Sep;33(3) 129-134.

26. Impett EA, Schooler D, Tolman DL. To be seen and not heard: Femininity ideology and adolescent girls' sexual health. Arch Sex Behav, 2006, 35(2): 131-144.

27. Kiefer AM, Sanchez DT, Kalinka CJ, et al., How women's nonconscious association of sex with submission relates to their subjective sexual arousability and ability to reach orgasm. Sex Roles, 2006, 55: 83-94.

28. Sanchez DT, Crocker J, Boike KR. Doing gender in the bedroom: investing in gender norms and the sexual experience. Pers Soc Psychol Bull, 2005, 31(10): 1445-55.

29. Tourangeau R, Yan T. Sensitive questions in surveys. Psychol Bull, 2007, 133(5): 859-883.

30. Penfold SC, van Teijlingen ER, Tucker JS. Factors associated with self-reported first sexual intercourse in Scottish adolescents. BMC Research Notes, 2009, 2:42.

31. Haggstrom-Nordin E, Borneskog C, Eriksson M, Tyden T. Sexual behaviour and contraceptive use among Swedish high school students in two cities: comparisons between genders, study programmes, and over time. Eur J Contracept Reprod Health Care. 2011 Feb; 16(1): 36-46

32. Edgardh K. Sexual behaviour and early coitarche in a national sample of 17-year-old Swedish boys. Acta Paediatr, 2002, 91(9): 985-91.

33. Edgardh K, Lewin B, Nilsson B. Sexual experience and behaviour as reported by 17year-old girls and boys in Sweden. Scand J Sexol, 1999, 2: 41-60.

\section{Current knowledge on this subject}


- Pain during VIC is a frequent complaint among young Swedish women, of whom unknown proportions continue to have VIC despite pain.

- Young women who continue to have VIC despite pain run a theoretical risk of developing chronic pain associated with VIC.

- Previous qualitative research has found that diverse social processes such as social norms and demands affect young women's chances of attaining equal sexual pleasure in (hetero) sexual interactions.

\section{What this study adds}

- Almost half of the women who had had VIC reported an experience of pain and/or discomfort during VIC, and almost half of them continue to have VIC despite pain

- The major reason given for continuing to have VIC despite pain was that they regarded the partner's satisfaction as more important than their own

- The findings portray the complexity of "pain during VIC", and expand the understanding of influences of gender norms on young women's sexuality. 